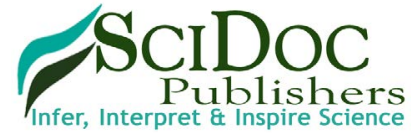

\section{Near-Infrared Spectroscopy Does Not Reliably Detect the Cerebral Status in Adults During Aortic Arch Surgery - A Retrospective Trial}

W. Baulig ${ }^{1 *}$, M. Bosshart ${ }^{2}$, K. Brueckner ${ }^{3}$, O.M. Theusinger ${ }^{4}$, M. Wilhelm ${ }^{5}$, B. Seifert ${ }^{6}$, D. Bettex ${ }^{\text {7\# }, \text { P.K. Buehler }}{ }^{\text {7\# }}$

${ }^{1}$ Department of Anesthesiology and Intensive Care Medicine, Klinik Im Park, Zurich, Switzerland.

${ }^{2}$ Institute of Anesthesiology and Intensive Care Medicine, Klinik Hirslanden, Zurich, Switzerland.

${ }^{3}$ Institute of Anesthesiology, Lindberg Clinic, Winterthur, Switzerland.

${ }^{4}$ Department of Anesthesiology, Balgrist University Hospital Zurich, Zurich, Switzerland.

${ }^{5}$ Division of Cardiovascular Surgery, University Hospital of Zurich, Zurich, Switzerland.

${ }^{6}$ Department of Biostatistics at Epidemiology, Biostatistics and Prevention Institute, University of Zurich, Zurich, Switzerland.

7 Institute of Anesthesiology, University Hospital Zurich, Zurich, Switzerland.

\# Both authors, D. Bettex and P.K. Buehler contributed equally to this work.

\title{
Abstract
}

Introduction: To investigate relationship between intraoperative regional oxygen cerebral desaturation $\left(\mathrm{rScO}_{2}\right)$ and the incidence of neurological deficit after aortic arch surgery in adult patients.

Methods: This study was conducted in a retrospective fashion. 53 patients undergoing aortic arch surgery with antegrade selective cerebral perfusion during deep hypothermic circulatory arrest between 2010 and 2012 were included.

ln all patients cerebral monitoring was performed using the near-infrared spectroscopy (NIRS) and a bispectral index electroencephalography (BIS). Cumulative values of $\mathrm{rScO}_{2}$ decrease $>20 \%$ of the baseline level ( $\mathrm{min} \%$ ) captured as the area under the curve ( $\mathrm{rScO}$, AUC) were calculated. Patients were divided in two groups: patients with ( $\mathrm{N}$-group) and without (Non-N group) a nonreversible neurological deficit, and patients with (D-group) and without (Non-D group) a reversible neurological deficit.

Results: Of 53 patients, 49 (93\%) suffered an aortic dissection Stanford Type A/De Bakey Type I and 4 (8\%) patients a De Bakey Type II. Six (11\%) patients died. Eleven (21\%) patients developed a nonreversible (stroke, hemorrhage) and $23(43 \%)$ patients a reversible neurological deficit (postoperative delirium). Postoperative delirium was significantly more frequent in the N-group (91\%) compared to the Non-N group (33\%). No significant difference was found for absolute $\mathrm{rScO}_{2}$ values $<50 \%$ and for the $\mathrm{rScO}, \mathrm{AUC}$ in both hemispheres between all groups.

Conclusion: Regional oxygen cerebral desaturation measured by NIRS appears to be a poor indicator for neurological outcome after aortic arch surgery in adults.

Keywords: Type A Aortic Dissection; Selective Antegrade Cerebral Perfusion; NIRS; Neurological Deficit.

\section{Introduction}

Type A (Stanford) De Bakey I aortic dissection involving the aortic arch remains a catastrophic event and seems to be associated with a center dependent in-hospital mortality of 11 to $26 \%$ [1-3]. Additionally, a 9 to $14.7 \%$ incidence of postoperative neurological impairment has been reported [4, 5]. Recently, in 278 patients with a repair of type A aortic dissection Lee and coworkers observed an incidence of $14.7 \%$ for postoperative early and late onset of nonreversible neurologic complications mainly including ischemic stroke and hypoxic encephalopathy. The mortality rate in this group was reported to be $43.9 \%$, which compared to the overall in-hospital mortality of $10.1 \%$, seems to be inappropriately high [6]. Additionally, to the occurrence of permanent neurological damage, the incidence of postoperative delirium as a reversible neurological deficit is considerably higher. Liu and colleagues found an incidence for postoperative delirium after type A aortic dissection surgery of $34 \%$ [7]. In the last decades, differ-

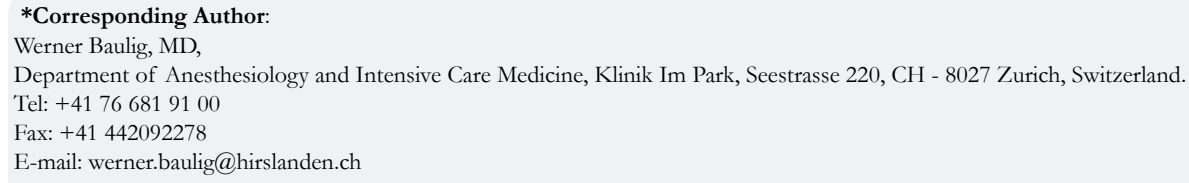

Citation: W. Baulig, M. Bosshart, K. Brueckner, O.M. Theusinger, M Wilhelm, et al., (2017) Near-Infrared Spectroscopy Does Not Reliably Detect the Cerebral Status in Adults During Aortic Arch Surgery - A Retrospective Trial. Int J Anesth Res. 5(6), 456-467. doi: http://dx.doi.org/10.19070/2332-2780-1700094

Copyright: W. Baulig ${ }^{\circ}$ 2017. This is an open-access article distributed under the terms of the Creative Commons Attribution License, which permits unrestricted use, distribution and reproduction in any medium, provided the original author and source are credited. 
ent surgical approaches of selective cerebral perfusion techniques during deep hypothermic cardiac arrest (DHCA), such as the unilateral antegrade cerebral perfusion (ACP) or the selective antegrade cerebral perfusion (SACP) have been developed to reduce the incidence of intraoperative cerebral ischemia [6-12].

Although these surgical protective measures have reduced the occurrence of reversible and nonreversible brain injury after aortic arch surgery, the incidences of these frequently fatal complications are still very high.

For several years transcranial Doppler (TCD), quantified electroencephalography (EEG), somatosensory evoked potentials (SSEP) and near infrared spectroscopy (NIRS) for detecting cerebral oxygenation and perfusion disturbances during these procedure have been well established in order to decrease morbidity and mortality [8]. The combination of EEG bispectral index monitor (BIS) with NIRS, allowing monitoring of brain electrical activity and the oxygen saturation of regional cerebral tissue $\left(\mathrm{rScO}_{2}\right)$ in a continuous, non-invasive, examiner independent way, has become more popular worldwide without any hard scientific evidence [9]. Some case reports and clinical series during ACP have shown that cerebral NIRS has been essential in diagnosing otherwise clinically silent arterial cannula malposition, catheter balloon migrations or disturbances of the contralateral cerebral perfusion [10-13]. However, results of different investigations show a doubtful clinical impact of NIRS in the context of emergency interventions such as aortic dissection [14, 15]. Especially the role of NIRS monitoring for early detection of clinically relevant cerebral perfusion disturbances and its predictive capability for the occurrence of postoperative reversible and irreversible cerebral dysfunction is unclear.

The aim of this retrospective study for patients undergoing aortic arch surgery for type A aortic dissection, was to investigate any association of changes in continuously measured bilateral $\mathrm{rScO}_{2}$ values, using near infrared spectroscopy with the incidence of postoperative neurological deficit. Defined primary outcomes were postoperative stroke, hypoxic encephalopathy and/or intracerebral hemorrhage (nonreversible neurological deficit); secondary outcome was the occurrence of postoperative delirium (reversible neurological deficit).

\section{Methods}

This study was approved by the Cantonal Ethics Committee Zurich, Switzerland (Registration Number: KEK-ZH-Nr. 20130028).

Between July 2010 and October 2012 perioperative data from 85 patients with acute aortic dissection type A undergoing aortic arch surgery at the University Hospital Zurich, Switzerland, were retrospectively collected. Inclusion criteria were type A aortic dissection following Stanford classification and performing SACP of the right and left common carotid artery DHCA. Exclusion criteria were: pre-existing acute or chronic pre-operative neurological deficit, DHCA of more than $10 \mathrm{~min}$ before SACP or incomplete documentation of the perioperative data, with particular interest in obtaining a full data set from the anesthetic procedures as well as the ICU stay.

\section{Anesthetic Techniques}

After arrival in the emergency department of the hospital, standard monitoring following ASA guidelines, as well as intravenous access and arterial cannulation introduced into the left radial artery were installed. Hemodynamic goals maintained were a systolic blood pressure between 80 and $90 \mathrm{mmHg}$ with a target heart rate of 60 to $80 \mathrm{bpm}$.

If not previously obtained, a multi-detector computed tomography (MCT) of the thorax and abdomen was performed to confirm the diagnosis [16]. Patients were transferred immediately afterwards to the cardiac operating theatre. Before induction of anesthesia standard monitoring for aortic arch surgery according to the institutional guidelines was applied. A bispectral index electroencephalography sensor (BIS) with four elements (BIS ${ }^{\mathrm{TM}}$ Quatro Sensor; Aspect Medical Systems, Inc Leiden, The Netherlands) was placed on the left side of the patient's forehead. (BIS VISTA $^{\text {TM }}$ Monitoring System, Aspect Medical Systems Inc. Norwood, MA, USA). For bifrontal detection of the regional cerebral oxygen saturation $\left(\mathrm{rScO}_{2}\right)$, two self-adhesive optodes (Disposable Adult SomaSensor SAFB-SM, Somanetics Corporation, Troy, MI, USA) were affixed as well on the patient's forehead, based on the manufacturer's recommendations, and connected to the INVOS ${ }^{\circledR}$ 5100 system (INVOS 5100 (Somanetics Corporation Troy, MI, USA).

Induction of anesthesia was achieved with intravenous propofol

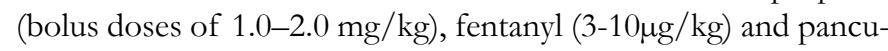
ronium $(0.1 \mathrm{mg} / \mathrm{kg})$. We maintained general anesthesia via a continuous infusion of propofol (target rate $0.07-0.2 \mathrm{mg} / \mathrm{kg} / \mathrm{min}$ ) and remifentanil $(0.1-0.3 \mu \mathrm{g} / \mathrm{kg} / \mathrm{min})$ titrated to BIS values of 40 - 60. After endotracheal intubation, the patients were mechanically ventilated (Dräger Primus EM anesthesia device, Drägerwerk AG \& CoKgAA, Lübeck, Germany) using standardized volumecontrolled modes.

Monitoring installed post induction of general anesthesia prior to surgical intervention included: a second arterial line, inserted in the right radial artery, a four-lumen central venous catheter (Arrow International, Reading, PA, USA), and an 8.5F introducer (Arrow International Reading, PA, USA) introduced into the right internal jugular vein in order to install a pulmonary catheter, enabling continuous measurement of cardiac output and mixed venous oxygenation saturation as well as a thermistor tipped urinary bladder catheter.

In the absence of any contraindications, a transesophageal echocardiography probe (TEE, Philips Healthcare, Bothell, WA, USA) was introduced to confirm diagnosis and guidance of hemodynamic management. A loading dose of tranexamic acid (TXA) (15mg/kg body weight) over 20 min was administered followed by a continuous infusion of TXA of $1.5 \mathrm{mg} / \mathrm{kg} / \mathrm{h}$ during the procedure until four hours after arrival in the ICU.

\section{Surgical Techniques}

Following the preparation of the right subclavian artery heparin $100 \mathrm{IU}$ per kilogram body weight was intravenously given, and an $8 \mathrm{~mm}$ vascular graft (FlowLine Bipore Heparin, JOTEC GmbH, Hechingen, Germany) was anastomosed in end-to-side fashion to the infraclavicular right subclavian artery. Arterial cannulation 
was carried out with a 20-French (Fr), cannula (Elongated OnePiece Arterial Cannula, Medronic, Minneapolis, MN, US) inserted through the vascular graft and connected to the extracorporeal circuit. The right subclavian artery distally to the anastomosis was entangled by a vessel loop to avoid hyperperfusion of the right upper limb. Alternatively, depending on the surgeon's preference, the arterial cannula was inserted directly after open puncture of the subclavian artery.

Following a median sternotomy and opening of the pericardium anticoagulation for the CPB was completed by administration of an additional dose of heparin 200 IU per kilogram of body weight targeting an activated clotting time (ACT) of above 400 seconds.

After cannulating the right atrial appendage with a double-staged cannula CPB was started. Patients were cooled down to a bladder temperature $\left(\mathrm{Temp}_{\mathrm{blad}}\right)$ of $28^{\circ} \mathrm{C}$, Additionally oesophageal temperature $\left(\mathrm{Tem}_{\text {poesoph }}\right)$ was measured. Once the target temperature was reached, extracorporeal circulation was stopped, the brachiocephalic trunk was clamped, and the ACP was started. The ascending aorta was incised and the heart was arrested by administration of Bretschneider cardioplegia solution directly into the coronary ostia. An additional perfusion catheter for ACP was inserted into the ostium of the left common carotid artery. SACP was performed at a flow of $8-15 \mathrm{ml} / \mathrm{kg} / \mathrm{min}$ achieving a target perfusion pressure between $40-60 \mathrm{mmHg}$ at bladder temperatures of ca. $28^{\circ} \mathrm{C}$ [17]. A Fogarty catheter occluded the ostium of the left subclavian artery to maintain the perfusion pressure in the cerebral circulation and to avoid possible steal phenomenon. The surgical technique of hemi-arch and frozen stent graft arch replacement have been described elsewhere [18]. Once the aortic arch repair was completed, the aortic graft was cannulated to restart the systemic CPB and rewarm the patient. During rewarming, the surgeons peformed the proximal anastomosis between supracoronary aorta and graft, or in case of destruction of the aortic root, a composite graft was implanted which was then connected to the graft in the distal ascending aorta and arch.

During rewarming of the patient, the rate of body temperature increase via the $\mathrm{CPB}$ was controlled to warrant a temperature gradient of less than $10^{\circ} \mathrm{C}$ between the venous inflow and the heat exchanger of the CPB. After the target bladder $\left(\right.$ Temp $\left._{\text {blad }}\right)$ and esophageal $\left(\mathrm{Tem}_{\text {pesoph }}\right)$ temperature of respectively $35^{\circ}$ and $36^{\circ} \mathrm{C}$ was reached, extracorporeal circulation was weaned off. Following meticulous hemostasis, the chest was closed according to current surgical standards.

\section{Cerebral Monitoring}

In all patients, both techniques of cerebral monitoring were used: the unilateral recording of BIS and the bifrontal detection of regional cerebral oxygen saturation $\left(\mathrm{rScO}_{2}\right)$ measured by NIRS. The principles of spatially resolved NIRS and the INVOS ${ }^{\circledR} 5100$ system have been investigated and described in detail in previous studies [19-21]. A decrease of the absolute $\mathrm{rScO}_{2}$ value below $50 \%$ or a decrease by $>20 \%$ of the initial measured baseline value was considered as threshold values, conform with previous defined standards [22]. Additionally, the calculated amount of the $\mathrm{rScO}_{2}$ Area Under the Curve ( $\left.\mathrm{rScO}_{2} \mathrm{AUC}\right)$, defined as the time (min) spent below the threshold multiplicated with the magnitude of the decrease of $\mathrm{rScO}_{2}$ below the threshold (\%), has been shown to be associated with the incidence of cerebral damage [23, 24].
The units of the $\mathrm{rScO}_{2}$ AUC are $\mathrm{min} \%$. In 2011, the algorithm for automatically detection of the $\mathrm{rScO}_{2}$ AUC was implemented in the INVOS ${ }^{\circledR} 5100$ system. At the time of this retrospective study, there were no standardized treatment guidelines for the event of a significant drop of $\mathrm{rScO}_{2}$ (decrease of $>20 \%$ of the baseline value of $\mathrm{rScO}_{2}$ ) available in the literature. Desaturations were treated at the discretion of the attending anesthetists.

\section{Demographic and Postoperative Data Collection}

From all patients included in this study, the demographic data and medical history were collected postoperatively via electronic patient records. The type of the acute aortic dissection, as well as the extend of the dissection into the carotid and vertebral arteries were recorded in the operation protocol. The following data was obtained form the documentation in the intensive care unit: the incidence of postoperative delirium, stroke, intracerebral hemorrhage, postoperative death, repeated surgery, peri-and postoperative occurrence of atrial fibrillation (AF), continuous veno-venous hemofiltration/dialysis, ventilation time $\left(\right.$ Vent $\left._{\text {time }}\right)$, ICU stay $\left(\mathrm{ICU}_{\text {stay }}\right)$ and length of hospital stay ( Hospital $\left._{\text {stay }}\right)$ in addition to the need and result of a cranial tomography.

The primary outcome was defined as the occurrence of postoperative nonreversible neurological deficit, presented as an ischemic stroke and/or intracerebral hemorrhage, confirmed by a neurological examination and cranial imaging (CT or MRI scan). Secondary outcome was determined by the appearance of a postoperative delirium, which was defined as a reversible neurological deficit.

A positive diagnosis of a postoperative delirium was made using the Richmond Agitation and Sedation Scale (RASS) with a value $>1+$ (the patient being restless, anxious or apprehensive with non-aggressive or vigorous movements) and the Intensive Care Delirium Screening Checklist (ICDSC) if the recorded score was $\geq 4$ up to the maximum of 8 .

\section{Data Collection from the Anesthesia Protocol}

The following intraoperative data were obtained from documentation in the anesthetic protocol: BIS, regional cerebral oxygen saturation of the left $\left(\mathrm{rScO}_{2 \text { left }}\right)$ and right $\left(\mathrm{rScO}_{2 \text { right }}\right)$ frontal/ parietal cortex, heart rate (HR), mean arterial pressure (MAP), pulse oximetric oxygen saturation values $\left(\mathrm{SpO}_{2}\right)$, central venous pressure (CVP), systolic, mean and diastolic pulmonary arterial pressure $\left(\mathrm{PAP}_{\text {syt } / \text { mean/diast }}\right)$, mixed venous oxygen saturation values $\left(\mathrm{SvO}_{2}\right)$, continuous cardiac output $(\mathrm{CCO})$, bladder $\left(\mathrm{Temp}_{\mathrm{blad}}\right)$ and oesophageal $\left(\right.$ Temp $\left._{\text {oesoph }}\right)$ temperature, inspired oxygen content $\left(\mathrm{FiO}_{2}\right)$, end expiratory carbon dioxide tension $\left(\mathrm{ETCO}_{2}\right)$, inspiratory (Pinsp) and end-expiratory (PEEP) ventilation pressures as well as data from routinely performed arterial blood gas analyses. While on CPB continuous blood gas analysis was performed using an optical fluorescence and reflectance based in-line (CDI blood parameter monitoring System 500 TM, Terumo cardiovascular Systems Corporation, Japan). The CDI system was intermittently calibrated by means of arterial blood gas analyses. Additionally, the maximum and minimum results of the following measures: bladder temperature (temp $\mathrm{plad}_{\text {bleep }}$ ), bladder (Temp $\left.\mathrm{blad}_{\mathrm{d}} \mathrm{SACP}\right)$ and

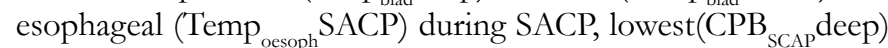
and highest $\left(\mathrm{CPB}_{\mathrm{SCAP}}\right.$ high) blood flow during SACP, lowest $\mathrm{FiO}_{2}$ during SACP ( $\mathrm{FiO}_{2 \mathrm{SCAP}}$ deep), lowest $\mathrm{PaO}_{2}$ during SCAP (Pa- 
$\mathrm{O}_{2 \mathrm{SCAP}}$ deep), lowest $\left(\mathrm{PaO}_{2 \mathrm{SCAP}}\right.$ deep) and highest $\left(\mathrm{PaCO}_{2 \mathrm{SCAP}}\right.$ high) $\mathrm{PaCO}_{2}$ during SCAP and lowest $\mathrm{Hb}$ during SCAP ( $\mathrm{Hb}_{\mathrm{SCAP}}$ deep) were collected. Furthermore, the intraoperative support with catecholamines, phosphodiesterase 3 inhibitors, vasodilators perioperative veno-arterial extracorporeal membrane oxygenation (ECMO), the amount of transfused red blood cells (RBC), fresh frozen plasma (FFP), platelets (Plt), fibrinogen (FBG), factor XIII, prothrombin complex (4 factor) and recombinant factor VIIa were listed separately.

Time requirements for the following procedures were documented at the end of the surgery: Anesthesia time, surgery time, CPB time, cumulative cross clamping time $\left(\mathrm{CrCl}_{\text {time }}\right)$ DHCA time $\left(\mathrm{DHCA}_{\text {time }}\right)$, SACP time $\left(\mathrm{SCAP}_{\text {time }}\right)$ and reperfusion time $\left(\right.$ Reperf $\left._{\text {time }}\right)$.

For analysis two patient groups were defined: Patients developing a non-reversible neurological deficit ( $\mathrm{N}$-group), patients without a nonreversible neurological deficit (Non-N group), patients developing a reversible neurological deficit (D-group) and patients without a reversible neurological deficit (Non-D group).

\section{Statistical Analysis}

Since the algorithm for the automatic detection of the $\mathrm{rScO}_{2} \mathrm{AUC}$ in the INVOS ${ }^{\circledR} 5100$ system was not available during the entire study period, the $\mathrm{rScO}_{2} \mathrm{AUC}$ for each patient were calculated separately using the periodically documented $\mathrm{rScO}_{2}$ values of the left and right forehead in the anesthesia protocol. Presuming that between two documented $\mathrm{rCCO}_{2}$ values the respective first documented value remained constant, the $\mathrm{rScO}_{2}$ AUC were calculated by both multiplying the magnitude of the decrease of $\mathrm{rScO}_{2}$ below the threshold value with the period between the respective two documented values in min and adding the results $(\min \%)$ of each period during the entire course.

All perioperative data were retrospectively collected. Discrete and binary data were compared using the Fisher's exact or chi square test. For ordinal and continuous data, the Mann-Whitney test was used for comparison between groups and the Wilcoxon signed rank test for comparison within the groups. Continuous data was presented as mean $\pm \mathrm{SD}$ ( $25 \%$ and $75 \%$ percentile). The $\mathrm{rScO}_{2}$ values at different points in time were compared using an analysis of variance for repeated measurements (ANOVA) including applying the Bonferroni correction. Because of the retrospective data collection, a p-value $<0.01$ was considered to be significant. The statistical analysis was performed using the SPSS version 21 (SPSS Science, Chicago, IL).

\section{Results}

A total of 85 patients were operated within the study period. Thirty-two had to be excluded by applying the exclusion criteria. Fifty-three patients were analyzed. In six (11\%) patient's death was inevitably: two patients died because of severe cerebral infarction, three as a result of multi organ failure and massive transfusion and one due to a postoperative pulmonary embolism. Eleven patients $(21 \%)$ developed a nonreversible and $23(43 \%)$ a reversible neurological deficit. Cerebral computed tomography confirmed a left hemispheric insult in three patients, a right hemispheric insult in two further patients and an insult involving the temporal lobe, the paraventricular region, the internal capsule, the brain steam and the infratentorial region in the remaining six patients.

Patient demographic data did not differ significantly within the two groups (Table 1a and b). In no patient, a cannula malposition causing a sudden drop of $\mathrm{rScO}_{2}$ of one of the hemispheres after initiation of the SACP was observed.

\section{Patients who Developed a Nonreversible Neurological defi- cit (N-group)}

Patient's characteristics and Type of aortic dissection of N-group and Non-N group are presented in table 1a. Table $2 \mathrm{a}$ shows that the mean $\mathrm{DHCA}_{\text {time }}$ was longer and the mean amount of administered FBG higher in the N-group compared to the Non-N group. However, this observation did not reach a level of significance $(p=0.05$ and $p=0.03$, respectively). In each patient of the $\mathrm{N}$ group the $\mathrm{rScO}$ AUC were always $>150 \%$ min on both frontal hemispheres. Although mean $\mathrm{rScO}_{2} \mathrm{AUC}$ values of both hemispheres $\left(\mathrm{rScO}_{2} \mathrm{AUC}_{\text {right }}\right.$ and $\mathrm{rScO}_{2} \mathrm{AUC}_{\text {leff }}$ ) were higher in the $\mathrm{N}$ group compared to the Non- $\mathrm{N}$ group, this observation cannot be considered significant as well due to $\mathrm{p}$ - values of 0.20 and 0.20 , respectively. Additionally, the mean $\mathrm{rScO}_{2} \mathrm{AUC}_{\text {left }}$ values showed a trend toward higher values compared to $\mathrm{rScO}_{2} \mathrm{AUC}_{\text {right }}$ in both groups (Table 3a). The mean of the deepest measured BIS values $\left(\mathrm{BI}_{\mathrm{SACP}}\right.$ deep) in the $\mathrm{N}$-group compared to the Non-N group was lower during the SACP period, without reaching any significant level $(\mathrm{p}=0.18)$, as shown in table 3a. Postoperative delirium occurred significantly more often in the N-group $(p=0.001)$ compared to the Non-N group (Table 4a). Cerebral computed tomography (CCT) was significantly more frequently performed in the N-group $(p<0.001)$ with pathological findings involving the left side of the brain $\left(\mathrm{CCT}_{\text {path leff }}\right)$ more frequently, confirmed by $\mathrm{p}<0.001$ in the $\mathrm{N}$-group compared to the Non-N group. The application of CVVHD was more common in the N-group, but this observation was not significant. All other outcome criteria as reoperation, atrial fibrillation, ventilation time, time spent in the ICU, length of stay and death did not significantly differ between both groups as shown in table $4 \mathrm{a}$.

\section{Patients who Developed a Reversible Neurological Deficit (D-group)}

Type of aortic dissection and known pre-existing conditions were not significantly different in the D-group compared to the control group (Non-D group). Aortic dissection combined with dissection of both common carotid arteries was significantly ( $\mathrm{p}=$ $0.007)$ more frequent in the $\mathrm{D}$-group. The combination of aortic dissection with unilateral dissection of the left or right common carotid artery occurred as well more frequently in the Dgroup but did not show any significant difference in incidence in both groups with $\mathrm{p}=0.01$ and $\mathrm{p}=0.08$, respectively (Table 1b). During the period of SACP we observed a trend towards lower blood flow $\left(\mathrm{CPB}_{\mathrm{SACP}}\right.$ deep) in the D-group compared to the Non-D group. The number of patients receiving dobutamine $(\mathrm{p}$ $=0.08)$, the mean volume of $\mathrm{RBC}(\mathrm{p}=0.01)$ and platelets $(\mathrm{p}=$ $0.061)$ transfused, total amount of FBG $(p=0.02)$ and factor XIII $(p=0.08)$ administered during the course of the procedure seemed to be higher in the D-group, however without achieving significance (Table $2 \mathrm{~b}$ ). All other measured parameters were not different in between the groups. During SCAP the mean right and left $\mathrm{rScO}_{2}$ in patients of the D-group showed a trend towards 
Table 1a. Patient Characteristics $(n=53)$, Data are Expressed as Number $(\%)$ or Mean \pm SD $(I Q R$ 25;75).

\begin{tabular}{|c|c|c|c|}
\hline & Group N & Group Non-N & p-value \\
\hline $\mathrm{N}$ & $11(21)$ & $42(79)$ & \\
\hline $\operatorname{Sex}(m / f)$ & $9 / 2(82 / 18)$ & $31 / 11(74 / 26)$ & 0.71 \\
\hline Age (ys) & $65.7 \pm 9.6(59.3 ; 72.2)$ & $62.5 \pm 14.7(57.9 ; 67.1)$ & 0.52 \\
\hline Weight (kg) & $79.1 \pm 13.1(70.3 ; 87.8)$ & $79.5 \pm 12.8(75.5 ; 83.5)$ & 0.81 \\
\hline Height & $175.4 \pm 7.9(170.1 ; 180.6)$ & $173.1 \pm 7.4(170.8 ; 175.4)$ & 0.4 \\
\hline BMI $\left(\mathrm{kg} / \mathrm{m}^{2}\right)$ & $25.6 \pm 2.6(23.8 ; 27.3)$ & $26.5 \pm 3.6(25.4 ; 27.6)$ & 0.48 \\
\hline \multicolumn{4}{|l|}{ Aortic dissection } \\
\hline Type A/I & $7(78)$ & $38(91)$ & \\
\hline Type A/I ruptured & $1(9)$ & $3(7)$ & \\
\hline Type A/II & $1(9)$ & $1(2)$ & \\
\hline Diss $_{C C A_{\text {right }}}$ & $4(36)$ & $6(14)$ & 0.19 \\
\hline Diss $\mathrm{CCA}_{\text {left }}$ & $3(27)$ & $7(17)$ & 0.42 \\
\hline Diss $\mathrm{CCA}_{\text {both }}$ & $2(18)$ & $4(10)$ & 0.21 \\
\hline \multicolumn{4}{|c|}{ Pre-excisting conditions } \\
\hline AHT & $8(73)$ & $23(55)$ & 0.28 \\
\hline CHD & $1(9)$ & 0 & 0.05 \\
\hline AVD & 0 & $4(10)$ & 0.29 \\
\hline Marfan disease & 0 & $1(2)$ & 0.61 \\
\hline A1DM/A2DM & $1(9)$ & 0 & 0.05 \\
\hline COPD & $3(27)$ & $2(5)$ & 0.02 \\
\hline CHRF & $1(9)$ & 0 & 0.05 \\
\hline Anemia & $1(9)$ & $2(5)$ & 0.58 \\
\hline Nicotine & $5(46)$ & $18(43)$ & 0.88 \\
\hline
\end{tabular}

Abbreviations: Group N, patients with nonreversible neurological deficit ; Group C, patients without nonreversible neurological deficit ; SD, standard deviation ; BMI, Body Mass Index; Type A/I, aortic dissection type A (Stanford classification) / I (DeBakey classification) = dissection of the ascending aorta, aortic arch and descending aorta; Type A/I ruptured, Type A/I with tear of all vessel wall units and bleeding in the space outside the aortic vessel ; Type A/II, aortic dissection type A (Stanford classification) /II (DeBakey classification) = dissection confined to the ascending aorta ; Diss CCA $_{\text {right }}$, Dissection with participation of the right common carotid artery; Diss CCA , Dissection with participation of left common carotid artery; Diss CCA , Dissection with participation of both common carotid arteries; AHT, Arterial Hypertension ; CHD, Coronary Heart Disease; AVD, Aortic Valve Disease; A1DM/A2DM; Diabetes mellitus Class A1 or A2; COPD, Chronic Obstructive Pulmonary Disease ; CHRF, Chronic Renal Failure.

Table 1b. Patient characteristics $(n=53)$, data are expressed as number $(\%)$ or mean \pm SD $(I Q R ~ 25 ; 75)$.

\begin{tabular}{|c|c|c|c|}
\hline & Group D & Group Non-D & p-value \\
\hline $\mathrm{N}$ & $23(43)$ & $30(57)$ & \\
\hline $\operatorname{Sex}(m / f)$ & $18 / 5(78 / 22)$ & $22 / 8(73 / 27)$ & 0.76 \\
\hline Age (ys) & $65.4 \pm 13.3(57.0 ; 76.0)$ & $61.5 \pm 14.1(50.8 ; 73.3)$ & 0.36 \\
\hline Weight (kg) & $78.2 \pm 10.8(70.5 ; 85.0)$ & $80.3 \pm 14.1(69.8 ; 90.2)$ & 0.67 \\
\hline Height & $174.4 \pm 8.3(168.0 ; 178.0)$ & $172.9 \pm 6.8(168.8 ; 177.3)$ & 0.56 \\
\hline BMI $\left(\mathrm{kg} / \mathrm{m}^{2}\right)$ & $25.7 \pm 3.0(23.7 ; 27.8)$ & $26.8 \pm 3.7(24.6 ; 29.7)$ & 0.33 \\
\hline \multicolumn{4}{|l|}{ Aortic dissection } \\
\hline Type A/I & $22(96)$ & $25(83)$ & \\
\hline Type A/I ruptured & $1(4)$ & $3(10)$ & \\
\hline Type A/II & 0 & $2(7)$ & \\
\hline Diss CCA right $_{\text {. }}$ & $7(30)$ & $3(10)$ & 0.08 \\
\hline Diss $\mathrm{CCA}_{\text {left }}$ & $8(35)$ & $2(7)$ & 0.01 \\
\hline Diss CCA $\mathrm{Coth}_{\text {bo }}$ & $5(22)$ & $1(3)$ & 0.007 \\
\hline \multicolumn{4}{|c|}{ Pre-excisting conditions } \\
\hline AHT & $15(65)$ & $16(53)$ & 0.42 \\
\hline CHD & 1(4) & 0 & 0.43 \\
\hline AVD & $2(9)$ & $2(7)$ & 1.00 \\
\hline Marfan disease & 0 & $1(3)$ & 1.00 \\
\hline A1DM/A2DM & 0 & $1(3)$ & 1.00 \\
\hline COPD & $3(13)$ & $2(7)$ & 0.64 \\
\hline CHRF & $1(4)$ & 0 & 0.43 \\
\hline Anemia & 0 & $3(10)$ & 0.25 \\
\hline Nicotine & $10(44)$ & $13(43)$ & 1.00 \\
\hline
\end{tabular}


Abbreviations: Group D, patients with delirium (reversible neurological deficit); Group Non-D, patients without delirium; SD, standard deviation ; BMI, Body Mass Index ; Type A/I, aortic dissection type A (Stanford classification) / I (DeBakey classification) = dissection of the ascending aorta, aortic arch and descending aorta ; Type A/I ruptured, Type A/I with tear of all vessel wall units and bleeding in the space outside the aortic vessel; Type A/II, aortic dissection type A (Stanford classification) /II (DeBakey classification) = dissection confined to the ascending aorta; Diss CCA $A_{\text {right }}$ Dissection with participation of the right common carotid artery; Diss CCA ${ }_{\text {left }}$ Dissection with participation of left common carotid artery; Diss $\mathrm{CCA}_{\text {both }}$, Dissection with participation of both common carotid arteries; AHT, Arterial Hypertension; CHD, Coronary Heart Disease ; AVD, Aortic Valve Disease ; A1DM/A2DM ; Diabetes mellitus Class A1 or A2 ; COPD, Chronic Obstructive Pulmonary Disease; CHRF, Chronic Renal Failure.

Table 2a. Data of the intraoperative course of patients with nonreversible neurological deficit (group N) and without nonreversible neurological deficit (group Non-N), data are expressed as number (\%) or mean \pm SD (IQR 25;75).

\begin{tabular}{|c|c|c|c|}
\hline & Group N & Group Non-N & p-value \\
\hline Surgery $_{\text {time }}, \min$ & $411.8 \pm 140.3(288 ; 564)$ & $374.9 \pm 120.9(290 ; 426)$ & 0.56 \\
\hline $\mathrm{CPB}_{\text {time }}, \min$ & $232.8 \pm 79.0(159 ; 258)$ & $218.6 \pm 84.0(152 ; 265)$ & 0.55 \\
\hline $\mathrm{CrCl}_{\text {time }}, \min$ & $127.2 \pm 57.9(65 ; 188)$ & $125.9 \pm 53.2(82 ; 160)$ & 0.96 \\
\hline $\mathrm{DHCA}_{\text {time }}, \min$ & $2.0 \pm 2.3(0 ; 3.0)$ & $0.8 \pm 1.4(0 ; 0.5)$ & 0.05 \\
\hline $\mathrm{SACP}_{\text {time }}, \mathrm{min}$ & $55.1 \pm 35.7(29 ; 82)$ & $43.1 \pm 22.3(30 ; 57)$ & 0.54 \\
\hline Reperf $_{\text {time }}, \min$ & $69.1 \pm 38.4(35 ; 111)$ & $59.4 \pm 39.2(34 ; 77)$ & 0.35 \\
\hline $\mathrm{Temp}_{\text {blad }}$ deep, ${ }^{\circ} \mathrm{C}$ & $26.0 \pm 2.4(24 ; 28)$ & $26.9 \pm 2.7(26 ; 28)$ & 0.20 \\
\hline $\mathrm{CPB}_{\mathrm{SACP}}$ deep, $1^{*} \mathrm{~min}^{-1}$ & $0.8 \pm 0.2(0.7 ; 1.0)$ & $0.9 \pm 0.3(0.7 ; 1.1)$ & 0.54 \\
\hline $\mathrm{CPB}_{\mathrm{SACP}}$ high, $1 * \mathrm{~min}^{-1}$ & $2.8 \pm 1.3(1.8 ; 3.7)$ & $2.9 \pm 1.3(1.8 ; 4.0)$ & 0.89 \\
\hline $\mathrm{FiO}_{2 \mathrm{SACP}}$ deep & $0.37 \pm 0.05(0.3 ; 0.4)$ & $0.37 \pm 0.07(0.3 ; 0.4)$ & 0.56 \\
\hline $\mathrm{PaCO}_{2 S A C P}$ deep, $\mathrm{kPa}$ & $4.0 \pm 0.9(3.9 ; 4.8)$ & $4.0 \pm 0.7(3.6 ; 4.7)$ & 0.73 \\
\hline $\mathrm{PaCO}_{2 S A C P}$ high, $\mathrm{kPa}$ & $5.1 \pm 0.9(4.8 ; 5.6)$ & $5.5 \pm 1.0(5.1 ; 6.0)$ & 0.32 \\
\hline $\mathrm{PaO}_{2 \mathrm{SACP}}$ deep, $\mathrm{kPa}$ & $27 \pm 6.5(23.9 ; 32.8)$ & $26.4 \pm 7.8(22.1 ; 32.5)$ & 0.67 \\
\hline $\mathrm{Hb}_{\mathrm{SACP}}$ deep, $\mathrm{g}^{*} \mathrm{dl}^{-1}$ & $8.1 \pm 2.1(6.4 ; 10.6)$ & $7.9 \pm 1.6(6.5 ; 9.2)$ & 0.76 \\
\hline $\mathrm{Temp}_{\text {blad }} \mathrm{SACP},{ }^{\circ} \mathrm{C}$ & $28.6 \pm 2.1(27.9 ; 30.1)$ & $28.3 \pm 3.0(27.7 ; 30.1)$ & 0.61 \\
\hline $\mathrm{Temp}_{\mathrm{tymp}} \mathrm{SACP},{ }^{\circ} \mathrm{C}$ & $25.5 \pm 3.6(23.7 ; 28.0)$ & $25.2 \pm 2.7(24.0 ; 27.4)$ & 0.91 \\
\hline IABP & 0 & $2(4.8)$ & 0.46 \\
\hline ECMO & 0 & $1(2.4)$ & 0.61 \\
\hline Nor-Epi & $11(100)$ & $42(100)$ & 1.00 \\
\hline Epi & $5(45.5)$ & $15(35.7)$ & 0.55 \\
\hline Dob & $4(36.4)$ & $14(33.3)$ & 0.85 \\
\hline Mil & $4(36.4)$ & $9(21.4)$ & 0.31 \\
\hline Glyc & $1(9.1)$ & $2(4.8)$ & 0.58 \\
\hline Phen & $1(9.1)$ & $1(2.4)$ & 0.23 \\
\hline RBC & $6.2 \pm 7.4(0 ; 8.0)$ & $5.0 \pm 7.4(0 ; 6.0)$ & 0.46 \\
\hline FFP & $2.6 \pm 6.9(0 ; 2.0)$ & $2.0 \pm 4.7(0 ; 1.8)$ & 0.99 \\
\hline Plt & $3.1 \pm 1.9(2.0 ; 4.0)$ & $2.4 \pm 2.1(1.0 ; 3.0)$ & 0.16 \\
\hline FBG,g & $8.0 \pm 3.8(6.0 ; 12.0)$ & $5.4 \pm 3.8(3.5 ; 8.0)$ & 0.03 \\
\hline F XIII, IU & $1568 \pm 1300(1250 ; 1250)$ & $988 \pm 789(0 ; 1250)$ & 0.13 \\
\hline Prothromplex, IU & $1546 \pm 1369(500 ; 2000)$ & $1238 \pm 1128(375 ; 2000)$ & 0.48 \\
\hline rFVIIa & $1(0 ; 0)$ & $1(0 ; 0)$ & 0.23 \\
\hline
\end{tabular}

Abbreviations: $\mathrm{CPB}$ time, periode of cardiopulmonary bypass in min; $\mathrm{CrCl}$ time, periode of clamping the aortic vessel in min; DHCA $\mathrm{D}_{\text {time }}$, periode of deep hypothermic cardiac arrest in min; $\mathrm{SACP}_{\text {time }}$, periode of selective antegrade cerebral perfusion in min; Reperf time $_{\text {, periode of reperfusion in min ; Temp }}$, deepest temperature during DHCA and selective antegrade cerebral perfusion (SACP) in ${ }^{\circ}$ Celsius; $\mathrm{CPB}_{\mathrm{SACP}}$ deep and $\mathrm{CPB}_{\mathrm{SACP}}$ high, deepest and highest blood flow during $\mathrm{SACP}$; FiO ${ }_{2 \mathrm{SACP}}$ deep, deepest inspired Oxygen content during $\mathrm{SACP} ; \mathrm{PaCO}_{2 \mathrm{SACP}}$ deep and $\mathrm{PaCO}_{2 \mathrm{SACP}}$ high, deepest and highest arterial carbon dioxide tension during $\mathrm{SACP}$; $\mathrm{PaO}{ }_{2 \mathrm{SACP}}$ deep, deepest arterial oxygen content during SACP; $\mathrm{Hb}_{\mathrm{SACP}}$ deep; deepest haemoglobin content $(\mathrm{g} / \mathrm{dl})$ during SACP; Temp $\mathrm{P}_{\text {blad }} \mathrm{SACP}_{\text {and Temp }} \mathrm{SACP}_{\text {tym }}$, deepest bladder and tympanic temperature during SACP; IABP, inta-aortal ballon pump; ECMO, extracorporeal membrane oxygenation; Nor-Epi; Norepinephrine; Epi, Epinephrine; Dob, Dobutamine; Mil, Milrinone; Glyc; Glyceroltrinitrat; Phen, Phentolamine mesilate; RBC, packed red blood cells; FFP, fresh frozen plasma concentrates; Plt, platelet concentrates; FBG, fibrinogen in gram (g); F XIII, coagulation factor XIII in international units (IU); Prothromplex, components of coagulation factor II, VII, IX, X and Protein $\mathrm{C}$ and $\mathrm{S}$ concentrations, quantified in international units (IU); rFVIIa, recombinant human coagulation factor VIIa.

higher values than in the Non-D group $(\mathrm{p}=0.08$ and $\mathrm{p}=0.04$, respectively) and the mean of the deepest measured BIS values (BIS $_{\text {ACP }}$ deep) were lower during the SACP period, but again, without reaching any significance $(p=0.02)$, as shown in table $3 b$. No statistical significant differences between the groups were found in the $\mathrm{rScO}_{2} \mathrm{AUC}$ of both hemispheres, although the $\mathrm{rScO}_{2} \mathrm{AU}$ -
$\mathrm{C}_{\text {right }}$ showed a trend towards higher values and the $\mathrm{rScO}_{2} \mathrm{AUC}_{\text {left }}$ towards lower values in the D-group compared to the Non-D group. Two patients in each group showed no significant decrease of $\mathrm{rScO}_{2}$ during the course of the procedure, with an $\mathrm{rScO}_{2} \mathrm{AUC}$ value of zero. Cerebral computed tomography (CCT) was significantly more frequently performed in the D-group $(\mathrm{p}<0.001)$. 
Table 2b. Data of the intraoperative course patients with delirium (group D) and without delirium (group Non-D), data are expressed as number $(\%)$ or mean \pm SD (IQR $25 ; 75)$.

\begin{tabular}{|c|c|c|c|}
\hline & Group D & Group Non-D & p-value \\
\hline Surgery $_{\text {time }}, \min$ & $399.7 \pm 127.1(290 ; 478)$ & $369.4 \pm 123.2(291 ; 415)$ & 0.52 \\
\hline $\mathrm{CPB}_{\text {time }}, \min$ & $226.9 \pm 88.5(151 ; 265)$ & $217.5 \pm 78.8(157 ; 259)$ & 0.88 \\
\hline $\mathrm{CrCl}_{\text {time }}, \min$ & $127.6 \pm 65.5(67 ; 188)$ & $125.1 \pm 43.6(97 ; 196)$ & 0.67 \\
\hline DHCA $_{\text {time }}, \min$ & $1.4 \pm 2.2(0 ; 3.0)$ & $0.8 \pm 1.2(0 ; 2.0)$ & 0.54 \\
\hline $\mathrm{SACP}_{\text {time, }}, \mathrm{min}$ & $43.4 \pm 22.1(26 ; 60)$ & $47.2 \pm 28.4(33 ; 57)$ & 0.55 \\
\hline Reperf $_{\text {time }}, \min$ & $62.6 \pm 33.6(34 ; 78)$ & $66.5 \pm 43.1(33 ; 82)$ & 0.57 \\
\hline $\mathrm{Temp}_{\text {blad }}$ deep, ${ }^{\circ} \mathrm{C}$ & $26.4 \pm 2.8(24.2 ; 28)$ & $27.0 \pm 2.5(25.8 ; 28)$ & 0.54 \\
\hline $\mathrm{CPB}_{\mathrm{SACP}}$ deep, $1^{*} \mathrm{~min}^{-1}$ & $0.8 \pm 0.3(0.6 ; 1.0)$ & $1.0 \pm 0.3(0.9 ; 1.1)$ & 0.02 \\
\hline $\mathrm{CPB}_{\mathrm{SACP}}$ high, $1^{*} \mathrm{~min}^{-1}$ & $2.9 \pm 1.4(1.6 ; 4.0)$ & $2.9 \pm 1.2(2.0 ; 3.7)$ & 0.91 \\
\hline $\mathrm{FiO}_{2 \mathrm{SACP}}$ deep & $0.37 \pm 0.06(0.3 ; 0.4)$ & $0.36 \pm 0.07(0.3 ; 0.4)$ & 0.63 \\
\hline $\mathrm{PaCO}_{2 \mathrm{SACP}}$ deep, $\mathrm{kPa}$ & $4.1 \pm 0.8(3.8 ; 4.7)$ & $4.0 \pm 0.8(3.5 ; 4.7)$ & 0.56 \\
\hline $\mathrm{PaCO}_{2 S A C P}$ high, $\mathrm{kPa}$ & $5.4 \pm 0.9(5.0 ; 5.7)$ & $5.5 \pm 1.0(5.1 ; 5.9)$ & 0.87 \\
\hline $\mathrm{PaO}_{2 \mathrm{SACP}}$ deep, $\mathrm{kPa}$ & $26.4 \pm 8.2(21.6 ; 32.6)$ & $26.7 \pm 7.1(22.8 ; 32.7)$ & 0.94 \\
\hline $\mathrm{Hb}_{\mathrm{SACP}}$ deep, $\mathrm{g}^{*} \mathrm{dl}^{-1}$ & $8.3 \pm 1.7(7.1 ; 9.4)$ & $7.7 \pm 1.7(6.0 ; 9.2)$ & 0.22 \\
\hline $\mathrm{Temp}_{\text {blad }} \mathrm{SACP},{ }^{\circ} \mathrm{C}$ & $28.0 \pm 2.0(26.8 ; 30.0)$ & $28.6 \pm 3.3(27.9 ; 30.3)$ & 0.25 \\
\hline Temp $_{\mathrm{tvmp}} \mathrm{SACP},{ }^{\circ} \mathrm{C}$ & $24.8 \pm 3.2(22.4 ; 27.8)$ & $25.6 \pm 2.5(24.4 ; 27.7)$ & 0.20 \\
\hline IABP & $1(4.3)$ & $1(3.3)$ & 1.00 \\
\hline ECMO & 0 & $1(3.3)$ & 1.00 \\
\hline Nor-Epi & $23(100)$ & $30(100)$ & 1.00 \\
\hline Epi & $9(39.1)$ & $11(36.7)$ & 1.00 \\
\hline Dob & $11(47.8)$ & $7(23.3)$ & 0.08 \\
\hline Mil & $7(30.4)$ & $6(20.0)$ & 0.52 \\
\hline Glyc & $1(4.3)$ & $2(6.7)$ & 1.00 \\
\hline Phen & 0 & $2(6.7)$ & 0.50 \\
\hline RBC & $6.6 \pm 5.9(1.0 ; 8.0)$ & $4.3 \pm 8.3(0 ; 4.0)$ & 0.01 \\
\hline FFP & $2.7 \pm 5.5(0 ; 4.0)$ & $1.7 \pm 4.9(0 ; 0)$ & 0.25 \\
\hline Plt & $2.8 \pm 1.7(2.0 ; 4.0)$ & $2.3 \pm 2.3(1.0 ; 3.0)$ & 0.06 \\
\hline FBG,g & $7.2 \pm 3.7(4.0 ; 10.0)$ & $5.0 \pm 3.8(2.0 ; 8.0)$ & 0.02 \\
\hline F XIII, IU & $1370 \pm 1054(1250 ; 1250)$ & $905 \pm 789(0 ; 1250)$ & 0.08 \\
\hline Prothromplex, IU & $1543 \pm 1348(500 ; 2000)$ & $1117 \pm 1006(0 ; 2000)$ & 0.31 \\
\hline rFVIIa & $0.09 \pm 0.29(0 ; 0)$ & $0.18 \pm 099(0 ; 0)$ & 0.43 \\
\hline
\end{tabular}

Abbreviations: $\mathrm{CPB}$ time, periode of cardiopulmonary bypass in min; $\mathrm{CrCl}$ time, periode of clamping the aortic vessel in min; $\mathrm{DHCA}_{\text {time }}$, periode of deep hypothermic

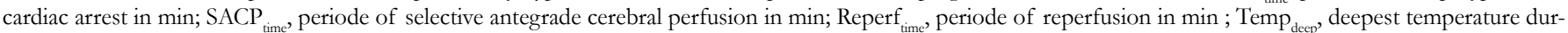
ing DHCA and selective antegrade cerebral perfusion (SACP) in ${ }^{\circ}$ Celsius; $\mathrm{CPB}_{\mathrm{SACP}}$ deep and $\mathrm{CPB}_{\mathrm{SACP}}$ high, deepest and highest blood flow during $\mathrm{SACP}$; FiO ${ }_{2 \mathrm{SACP}}$ deep, deepest inspired Oxygen content during SACP; $\mathrm{PaCO}_{2 \mathrm{ACP}}$ deep and $\mathrm{PaCO}_{2 \mathrm{ACP}}$ high, deepest and highest arterial carbon dioxide tension during $\mathrm{SACP}$; PaO ${ }_{2 \mathrm{ASACP}}$ deep,

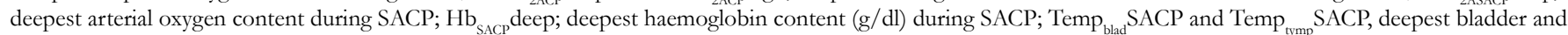
tympanic temperature during SACP; IABP, inta-aortal ballon pump; ECMO, extracorporeal membrane oxygenation; Nor-Epi; Norepinephrine; Epi, Epinephrine; Dob, Dobutamine; Mil, Milrinone; Glyc; Glyceroltrinitrat; Phen, Phentolamine mesilate; RBC, packed red blood cells; FFP, fresh frozen plasma concentrates; Plt, platelet concentrates; FBG, fibrinogen in gram (g); F XIII, coagulation factor XIII in international units (IU); Prothromplex, components of coagulation factor II, VII, IX, X and Protein $\mathrm{C}$ and $\mathrm{S}$ concentrations, quantified in international units (IU); rFVIIa, recombinant human coagulation factor VIIa.

Pathological findings on the right side of the brain (CCT $\left.\mathrm{T}_{\text {path right }}\right)$ were more frequently but not significantly $(\mathrm{p}=0.07)$ observed in the D-group if compared to the Non-D group. Ventilation time $(p<0.001)$, ICU stay $(p<0.001)$ and length of stay $(p<0.001)$ of the D-group were significantly longer compared to those in the Non-D group. Nonreversible neurological deficit, rate of reoperation, atrial fibrillation, application of CVVHD did not differ significantly between both groups (Table $4 \mathrm{~b}$ ).

No significant association was found between the occurrence of nonreversible (N-group) or reversible neurological deficit (D-

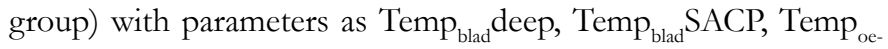

SACP, $\mathrm{CO}_{\text {SCAP }}$ deep, $\mathrm{CO}_{\text {SCAP }}$ high, $\mathrm{FiO}_{2 \mathrm{SCAP}}$ deep, $\mathrm{PaO}_{2 \mathrm{SCAP}}$ deep, $\mathrm{PaO}_{2 S C A P}$ high, $\mathrm{PaCO}_{2 \mathrm{SCAP}}$ high and $\mathrm{Hb}_{\mathrm{SCAP}}$ deep.

In the subgroup of patients who died, the mean $\mathrm{rScO}_{2} \mathrm{AUC}$ values detected on the left $(p=0.02)$ and right forehead $(p=0.40)$ were higher compared to the values detected in the surviving patients (Table 5), however this observation did not reach a significance level. In this group, mean surgery time showed a trend towards a longer time span and the mean transfusion of RBC was subsequent higher $(\mathrm{p}=0.05)$ but both observations did not achieve significance if compared to the surviving patients. The FFP transfused was significantly $(p=0.007)$ higher in the patients 
Table 3a. Intraoperative data of cerebral monitoring of patients with nonreversible neurological deficit (group N) and without nonreversible neurological deficit (group Non-N), data are expressed as number (\%) or mean \pm SD (IQR 25;75).

\begin{tabular}{|c|c|c|c|}
\hline & Group N & Group Non-N & p-value \\
\hline $\mathrm{rScO}_{2 \text { right }}$ initial & $69.0 \pm 10.3(63 ; 78)$ & $65.7 \pm 15.1(58 ; 74)$ & 0.44 \\
\hline $\mathrm{rScO}_{2 \text { left }}$ initial & $67.7 \pm 12.6(59 ; 79)$ & $66.1 \pm 15.2(60 ; 77)$ & 0.98 \\
\hline $\mathrm{rScO}_{2} \%_{\mathrm{ACP}} \mathrm{right}$ & $82 \pm 11(65 ; 100)$ & $86 \pm 49(64 ; 87)$ & 0.79 \\
\hline $\mathrm{rScO}_{2} \%{ }_{\mathrm{ACP}} \mathrm{left}$ & $67 \pm 16(54 ; 74)$ & $74 \pm 35(55 ; 88)$ & 0.61 \\
\hline $\mathrm{rScO}_{2 \text { right }}>20 \%$ & $11(100)$ & $36(85.7)$ & 0.18 \\
\hline $\mathrm{rScO}_{2 \text { left }}>20 \%$ & $11(100)$ & $39(92.9)$ & 0.36 \\
\hline $\mathrm{rScO}_{2 \text { right }}<50 \%$ & $8(72.7)$ & $31(73.8)$ & 0.94 \\
\hline $\mathrm{rScO}_{2 \text { left }}<50 \%$ & $8(72.7)$ & $33(78.6)$ & 0.68 \\
\hline $\mathrm{rScO}_{2} \mathrm{AUC}_{\text {right }} \% \mathrm{~min}$ & $2028 \pm 1895(362 ; 4356)$ & $1267 \pm 1690(164 ; 1589)$ & 0.20 \\
\hline $\mathrm{rScO}_{2} \mathrm{AUC}_{\text {left }} \% \mathrm{~min}$ & $2395 \pm 1928(593 ; 4710)$ & $1727 \pm 1803(364 ; 2725)$ & 0.20 \\
\hline $\mathrm{BIS}_{\mathrm{ACP}} \mathrm{deep}$ & $4.7 \pm 4.9(0 ; 7)$ & $10.2 \pm 11.8(1 ; 17)$ & 0.18 \\
\hline
\end{tabular}

Abbreviations: Nonreversible neurological deficit, neurological damage as stroke or intracerebral haemorrhage; $\mathrm{rScO}_{2 \mathrm{right}}$ initial and $\mathrm{rScO}$ 2left initial, first original measured regional cerebral oxygen saturation count $\left(\mathrm{rScO}_{2}\right)$ at right and left frontal side before induction anaesthesia (baseline value); $\mathrm{rScO}_{2} \%{ }_{\mathrm{ACP}} \mathrm{right}_{\mathrm{and}} \mathrm{rScO}_{2} \%{ }_{\mathrm{ACP}} \mathrm{left}$, deepest measured relative value (in $\%$ from the baseline value) of $\mathrm{rScO}_{2}$ on the right and left frontal side during antegrade cerebral perfusion ( $\mathrm{ACP}$ ); $\mathrm{rScO}{ }_{2}$ right $>20 \%$, regional cerebral oxygen saturation value decrease $>20 \%$ from the baseline value at right frontal area; $\mathrm{rScO}_{2}$ left $>20 \%$, regional cerebral oxygen saturation value decrease $>$ $20 \%$ from the baseline value at the left frontal area; $\mathrm{rScO}_{2}$ right $<50 \%$, regional cerebral oxygenation saturation value $<50 \%$ of the baseline value at the right frontal area; $\mathrm{rScO}_{2}$ left $<50 \%$, regional cerebral oxygenation saturation value $<50 \%$ of the baseline value at the left frontal area; $\mathrm{rScO}_{2} \mathrm{AUC}_{\text {right }}$, $\mathrm{rScO}_{2} \mathrm{AUC}_{\text {leff }}$, $\mathrm{BIS}_{\mathrm{ACP}}$ deep, deepest Bispectral Index EEG count during antegrade cerebral perfusion (ACP).

Table 3b. Intraoperative data of cerebral monitoring of patients with delirium (group D) and without delirium (group NonD), data are expressed as number $(\%)$ or mean \pm SD (IQR $25 ; 75)$.

\begin{tabular}{|c|c|c|c|}
\hline & Group D & Group Non-D & p-value \\
\hline $\mathrm{rScO}_{2 \text { right }}$ initial & $65.4 \pm 13.8(59 ; 72)$ & $67.0 \pm 15.3(60 ; 79)$ & 0.45 \\
\hline $\mathrm{rScO}_{2 \text { left }}$ initial & $64.8 \pm 14.2(60 ; 75)$ & $67.5 \pm 14.4(61 ; 76)$ & 0.71 \\
\hline $\mathrm{rScO}_{2} \%_{\mathrm{ACP}} \mathrm{right}$ & $92 \pm 45(68 ; 100)$ & $80 \pm 44(60 ; 84)$ & 0.08 \\
\hline $\mathrm{rScO}_{2} \%{ }_{\mathrm{ACP}} \mathrm{left}$ & $78 \pm 24(64 ; 87)$ & $68 \pm 37(50 ; 81)$ & 0.04 \\
\hline $\mathrm{rScO}_{2 \text { right }}>20 \%$ & $18(78.3)$ & $24(80.0)$ & 0.83 \\
\hline $\mathrm{rScO}_{2 \text { left }}>20 \%$ & $18(78.3)$ & $24(80.0)$ & 0.83 \\
\hline $\mathrm{rScO}_{2 \text { right }}<50 \%$ & $18(78.3)$ & $21(70.0)$ & 0.55 \\
\hline $\mathrm{rScO}_{2 \text { left }}<50 \%$ & $18(78.3)$ & $23(76.7)$ & 0.50 \\
\hline $\mathrm{rScO}_{2} \mathrm{AUC}_{\text {right }} \%$ min & $1769 \pm 1913(210 ; 3962)$ & $1162 \pm 1584(239 ; 1545)$ & 0.42 \\
\hline $\mathrm{rScO}_{2} \mathrm{AUC}_{\text {left }} \% \mathrm{~min}$ & $1653 \pm 1801(308 ; 2719)$ & $2029 \pm 1867(560 ; 3159)$ & 0.40 \\
\hline $\mathrm{BIS}_{\mathrm{ACP}} \mathrm{deep}$ & $6.1 \pm 10.0(0 ; 8)$ & $11.4 \pm 11(2.5 ; 19)$ & 0.02 \\
\hline
\end{tabular}

Abbreviations: Delirium, defined as a measured value $>+1$ based on the Richmond Agitation and Sedation $\mathrm{Scale}_{\text {( }}(\mathrm{RASS}) ; \mathrm{rScO}_{2 \mathrm{rimh}}$ initial and $\mathrm{rScO}_{2 \mathrm{eff}}$ initial, first original measured regional cerebral oxygen saturation count $\left(\mathrm{rScO}_{2}\right)$ at right and left frontal side before induction anaesthesia (baseline value); $\mathrm{rScO}{ }_{2}{ }_{\mathrm{ACP}} \mathrm{right}$ and $\mathrm{rScO}{ }_{2} \%{ }_{\mathrm{ACP}}$ left, deepest measured relative value (in $\%$ from the baseline value) of $\mathrm{rScO}_{2}$ on the right and left frontal side during antegrade cerebral perfusion (ACP); $\mathrm{rScO},>20 \%$, regional cerebral oxygen saturation value decrease $>20 \%$ from the baseline value at right frontal area; $\mathrm{rScO} 2$ left $>20 \%$, regional cerebral oxygen saturation value decrease $>20 \%$ from the baseline value at the left frontal area; $\mathrm{rScO}_{2 \text { ight }}<50 \%$, regional cerebral oxygenation saturation value $<50 \%$ of the baseline value at the right frontal area; $\mathrm{rScO}_{2 \text { left }}<50 \%$, regional cerebral oxygenation saturation value $<50 \%$ of the baseline value at the left frontal area; $\mathrm{rScO}_{2} \mathrm{AUC}_{\text {right }}$, $\mathrm{rScO}_{2} \mathrm{AUC}_{\text {left }}, \mathrm{BIS}_{\mathrm{ACP}}$ deep, deepest Bispectral Index EEG count during antegrade cerebral perfusion (ACP).

who died.

\section{Discussion}

The main findings of this retrospective study in patients undergoing aortic arch repair in deep hypothermic arrest and SACP are: (1) there was no association found between the primary or secondary outcomes and a decrease of $\mathrm{rScO}_{2}$ by more than $20 \%$ from baseline, a decrease of the absolute value of $\mathrm{rScO}_{2}<50 \%$ and a $\mathrm{rcO}_{2}$ AUC; with the primary outcome being defined as the incidence of postoperative stroke, hypoxic encephalopathy and/ or intracerebral hemorrhage, and the secondary outcome as the occurrence of postoperative delirium. (2) Postoperative delirium was significantly more frequent in the $\mathrm{N}$-group compared to the Non-N-group.

There seems to be no general consensus on the level of cerebral deoxygenation $\left(\mathrm{rScO}_{2}\right)$ representing a dangerous level and therefore an increased morbidity \& mortality risk during cardiovascular surgery. Samka et al., compared NIRS with the neurologic examination of patients undergoing carotid endarterectomy under regional anesthesia and demonstrated a reduction in $\mathrm{rScO}_{2}>20 \%$ from the baseline being associated with the development of neurological symptoms [22]. In patients during implantable cardio- 
Table 4a. Data of conducted investigations and outcome data of patients with nonreversible neurological deficit (group $\mathrm{N})$ and without nonreversible neurological deficit (group Non-N), data are expressed as number (\%) or mean \pm SD (IQR $25 ; 75)$.

\begin{tabular}{|c|c|c|c|}
\hline & Group N & Group Non-N & p-value \\
\hline CCT $_{\text {freq }}$ & $9(81.8)$ & $15(35.7)$ & 0.001 \\
\hline CCT $_{\text {path right }}$ & $1(9.1)$ & $1(2.4)$ & 0.23 \\
\hline CCT $_{\text {path left }}$ & $6(54.5)$ & 0 & $<0.001$ \\
\hline Delirium & $10(90.9)$ & $13(30.0)$ & 0.001 \\
\hline Re-Op & $4(36.4)$ & $11(26.2)$ & 0.51 \\
\hline AF & $6(54.5)$ & $17(40.5)$ & 0.40 \\
\hline Death & $2(18.2)$ & $4(9.5)$ & 0.42 \\
\hline CVVHD & $5(45.5)$ & $8(19.0)$ & 0.07 \\
\hline Vent $_{\text {time, }}, \mathrm{h}$ & $139.2 \pm 169.7(19.0 ; 214.0)$ & $86.0 \pm 140.0(12.0 ; 74.0)$ & 0.18 \\
\hline ICU $_{\text {star, }} \mathrm{h}$ & $170.5 \pm 171.2(35.0 ; 254.0)$ & $118.6 \pm 152.6(26.4 ; 141.0)$ & 0.28 \\
\hline Hospital $_{\text {stap }}, \mathrm{d}$ & $25.7 \pm 29.5(5.0 ; 33.0)$ & $14.2 \pm 10.6(7.5 ; 18.0)$ & 0.39 \\
\hline
\end{tabular}

Abbreviations: Nonreversible neurological deficit, neurological damage as stroke or intracerebrale haemorrhage; $\mathrm{CCT}_{\text {freq }}$, frequeny of cranial computed tomography (CCT) performed in the groups; CCT ${ }_{\text {ath right }}$, pathological CCT findings on the right side; CCT ${ }_{\text {path left }}$, pathological CCT findings on the left side; Delirium, defined as a measured value $>+1$ based on the Richmond Agitation and Sedation Scale (RASS); Re-Op, repeated operation; AF, atrial fibrillation; CVVHD, Continuous veno-venous

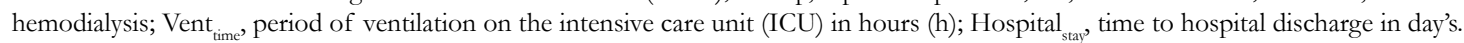

Table 4b. Data of conducted investigations and outcome data of patients with delirium (group D) and without delirium (group Non-D), data are expressed as number $(\%)$ or mean \pm SD (IQR 25;75).

\begin{tabular}{|c|c|c|c|}
\hline & Group D & Group Non-D & p-value \\
\hline CCT $_{\text {freq }}$ & $17(73.9)$ & $7(23.3)$ & $>0.001$ \\
\hline CCT $_{\text {path right }}$ & $5(21.7)$ & $1(3.3)$ & 0.07 \\
\hline CCT $_{\text {path left }}$ & $4(17.4)$ & $2(6.7)$ & 0.39 \\
\hline Delirium & $7(30.4)$ & $4(13.3)$ & 0.180 \\
\hline Re-Op & $8(34.8)$ & $7(23.3)$ & 1.00 \\
\hline AF & $12(52.2)$ & $11(36.7)$ & 0.28 \\
\hline Death & 0 & $6(20.0)$ & 0.03 \\
\hline CVVHD & $5(21.7)$ & $8(26.7)$ & 0.76 \\
\hline Vent $_{\text {time }}, \mathrm{h}$ & $161.7 \pm 185.2(36 ; 205)$ & $47.5 \pm 81.1(9 ; 34)$ & $<0.001$ \\
\hline ICU $_{\text {star }} \mathrm{h}$ & $214.8 \pm 157.6(113 ; 254)$ & $63.9 \pm 83.1(22 ; 72)$ & $<0.001$ \\
\hline Hospital $_{\text {star, }} \mathrm{d}$ & $24.9 \pm 21.4(12 ; 31)$ & $10.0 \pm 7.1(7 ; 13)$ & $<0.001$ \\
\hline
\end{tabular}

Abbreviations: Delirium, defined as a measured value $>+1$ based on the Richmond Agitation and Sedation Scale (RASS); CCT freq frequeny of cranial computed tomography (CCT) performed in the groups; $\mathrm{CCT}_{\text {p }}$, pathological CCT findings on the right side; CCT ${ }_{\text {pth left }}$, pathological CCT findings on the left side; Deficit ${ }_{\text {euro? }}$ nonreversible neurological deficit (stroke, intracerebral haemorrhage); Re-Op, repeated operation; AF, atrial fibrillation; CVVHD, Continuous veno-venous hemodialysis; Vent $_{\text {time }}$, period of ventilation on the intensive care unit (ICU) in hours (h); Hospital ${ }_{\text {stay }}$, time to hospital discharge in day's.

Table 5. Data of conducted investigations of patients who died $(n=6)$ or survived $(n=47)$, data are expressed as number $(\%)$ or mean \pm SD $($ IQR $25 ; 75)$.

\begin{tabular}{|c|c|c|c|}
\hline & Group death & Group survive & $\mathrm{p}$-value \\
\hline $\mathrm{rScO}_{2} \mathrm{AUC}_{\text {right }}, \% \mathrm{~min}$ & $2425 \pm 2958(1029 ; 5036)$ & $1297 \pm 1529(193 ; 1722)$ & 0.40 \\
\hline $\mathrm{rScO}_{2} \mathrm{AUC}_{\text {left }} \% \mathrm{~min}$ & $3779 \pm 2221(2187 ; 5315)$ & $1621 \pm 1648(427 ; 2530)$ & 0.02 \\
\hline surgery time, $\min$ & $501.8 \pm 160.9(352 ; 680)$ & $367.4 \pm 112.5(288 ; 420)$ & 0.04 \\
\hline $\mathrm{RBC}$ & $13.8 \pm 15.5(3.3 ; 26.3)$ & $4.2 \pm 5.0(0 ; 6.0)$ & 0.05 \\
\hline FFP & $7.7 \pm 9.2(0 ; 15.0)$ & $1.4 \pm 4.1(0 ; 0)$ & 0.007 \\
\hline
\end{tabular}

Abbreviations: $\mathrm{rScO}_{2} \mathrm{AUC}_{\text {right }}$ and $\mathrm{rScO}_{2} \mathrm{AUC}_{\text {left }}$, Area Under the Curve of each percent of regional cerebral oxygen saturation values $<80 \%$ multiplied with the time (\%min) from the right and left frontal side; RBC, red blood cell package; FFP, Fresh Frozen Plasma package. 
verter defibrillator testing Edmonds et al., discovered, that a loss of consciousness was accompanied by a decline of $\mathrm{rScO}_{2}>20 \%$ [25]. Based on these studies and the recommendations of Murkin and co-workers, the perilous level of cerebral desaturation in this retrospective investigation was defined as a decline of $\mathrm{rScO}_{2}>$ $20 \%$ of the baseline value and an AUC $>150 \%$ min [23]. The decrease of $\mathrm{rScO}_{2}$ by more than $20 \%$ from baseline, the decrease of the absolute value to $\mathrm{rScO}_{2}<50 \%$ and the $\mathrm{rScO}_{2}$ AUC in this investigation were not significantly different between patients who developed postoperative nonreversible (N-group) or reversible (D-group) deficit compared to those without any neurologic deficit (Non-N and Non-D-group). However, it is noteworthy that all patients who developed a postoperative nonreversible neurological deficit always showed a bilateral $\mathrm{rScO}_{2}$ AUC $>150 \% \mathrm{~min}$. Additionally, the bilateral $\mathrm{rScO}_{2}$ AUC showed a trend towards higher values in the $\mathrm{N}$-group compared to the Non-N group. In 46 patients scheduled for aortic arch surgery and SACP Olsson and colleagues reported a sensitivity up to $83 \%$ and a specificity up to $94 \%$ in identifying postoperative stroke, if $\mathrm{rScO}_{2}$ decreased to values between 76 to $85 \%$ of the baseline [10]. In their study, the relative $\mathrm{rScO}_{2}$ values measured during SACP were significantly lower in the ischemic compared to the apparently well-perfused hemisphere in the six patients who developed a stroke. The mean relative $\mathrm{rScO}_{2}$ values measured during SACP in our study were also found to be lower in patients developing a nonreversible neurological deficit compared to the patients without nonreversible neurological harm but this finding did not reach significance. Additionally, in the $\mathrm{N}$ - and Non- $\mathrm{N}$ group, mean relative $\mathrm{rScO}_{2}$ values of the left forehead tended to be lower compared to those measured on the right forehead without association to a likely stroke location. These findings could be explained by technical limitations of the NIRS and the detection of tissue saturation in a small area of extracranial and brain tissue, near a watershed area. All patients of the $\mathrm{N}$-group underwent cerebral computed tomography. In three patients a left hemispheric insult, in two patients a right hemispheric insult and in the remaining six patients' diverse cerebral insults were found in areas which cannot be monitored by a NIRS device: the temporal lobe, the paraventricular region, the intern capsule, the brain stem and the infratentorial area of the brain. Urbanski et al., investigated NIRS in 122 patients undergoing aortic arch surgery using unilateral cerebral perfusion [14]. They reported a presumed insufficient crossover perfusion in one patient following an intense drop of the absolute $\mathrm{rScO}_{2}$ value to $15 \%$. This was successfully treated by changing from uni- to bilateral perfusion of the brain feeding arteries. In the remaining 121 patients, no drop deeper than an absolute $\mathrm{rScO}_{2}$ value of $40 \%$ or $70 \%$ of the baseline $\mathrm{rCCO}_{2}$ was found, but five patients developed a permanent and nine a temporary neurological deficit. As in this retrospective investigation, they found no association between the occurrence of adverse neurological outcome and the values of regional cerebral oxygen saturation. In 200 patients undergoing coronary artery bypass graft surgery, Murkin and colleagues investigated the impact of corrected significant cerebral desaturations. They defined cerebral desaturations as a decrease of $\mathrm{rScO}_{2}$ below $70 \%$ of baseline for one minute or longer and profound desaturations where $\mathrm{rScO}_{2}$ AUC $<70 \%$ of baseline was $>150 \% \mathrm{~min}$. Significantly less major organ morbidity or death was reported in the intervention group of this study [23]. However, although the rate of stroke was lower in the intervention group compared to the not treated group, this finding was of no significance. It is worth mentioning, that the highest measured $\mathrm{rScO}_{2} \mathrm{AUC}$ values in this retrospective investigation were found in patients who did not suffer any nonreversible or reversible cerebral deficit. The highest measured $\mathrm{rScO}_{2}$ AUC value in the $\mathrm{N}$-group was $5253 \% \mathrm{~min}$, in the D-group without nonreversible cerebral deficit $6021 \% \mathrm{~min}$ and in the Non-N and Non-D-group $7131 \%$ min. $\mathrm{rScO}_{2}$ AUC values $>2000 \%$ min were found in 11 patients who did not suffer any cerebral deficit, in six patients of the $\mathrm{N}$-group and in eight patients of the D-group (data not shown). These findings additionally suggest that the oxygen saturation measurements with NIRS do not exclusively reflect the saturation of the brain tissue, but might be significantly influenced by the perfusion of extracerebral tissue. Recently Zanatta and Forti reported a supplementary patient related limitation of the NIRS by mentioning the significantly higher incidence of frontal brain atrophy in elderly patients [26]. This patient related condition might not allow an accurate measurement of cortical tissue oxygenation, because of a too low penetration depth in patients suffering from frontal cortical atrophy, even a sufficient cortical saturation level might not be picked up in these patient's due to the lack of penetration of NIRS.

As expected, the postoperative delirium was significantly more frequent in the $\mathrm{N}$-group compared to the Non-N group. The incidence of delirium post-stroke in non-surgical patients is estimated to vary from $13 \%$ to $48 \%$ and is independently associated with poor functional outcome, death and prolonged institutionalization [27]. In this investigation $64 \%$ of the $\mathrm{N}$-group and $38 \%$ of the Non-N group suffered from postoperative delirium. Although not significant, the $\mathrm{rScO}_{2} \mathrm{AUC}$ values of the D-group were noted to be higher on the right forehead whereas the $\mathrm{rScO}_{2}$ AUC values on the left side appeared lower compared to corresponding values of the Non-D group. These findings indicate that there is no association between a significant drop, the drop size and its duration of $\mathrm{rScO}_{2}$ measured by the NIRS in the context of predicting the incidence of a postoperative delirium.

Although not significant, the mean value of the deepest measured BIS during SACP was lower in the N-group and in the D-group compared to the corresponding Non-N and Non-D groups. Stecker et al., investigated the impact of moderate to deep hypothermia on brain electrical activity in 109 patients undergoing deep hypothermic circulatory arrest with neurophysiologic monitoring. The mean nasopharyngeal temperature when periodic complexes appeared in the EEG after cooling was $29.6 \pm 3^{\circ} \mathrm{C}$, EEG burst suppression appeared at $24.4 \pm 4^{\circ} \mathrm{C}$, and electroencephalic silence appeared at $17.8 \pm 4^{\circ} \mathrm{C}$ [28]. Burst suppression ratio (BSR), quantifying the percentage of suppressions during burst suppression pattern is integrated in the BIS algorithm. In ten healthy volunteers undergoing propofol infusion Bruhn et al., reported a linear correlation of BSR values $>40 \%$ with BIS values from 30 to zero [29]. Tobias et al., reported BIS values of $7 \pm 5,14 \pm 3$ and $37 \pm 12$ while the EEG showed $\leq 2,3-5$, and $\geq 6$ bursts $/ \mathrm{min}$ in 7 patients who received treatment with pentobarbital for an elevated intracranial pressure [30]. The observation of deepest BIS values during SACP of 0 to 7 in the $\mathrm{N}$-group, $0-8$ in the D-group compared to $1-17$ in the Non-N group and 2.5 to 19 in the Non$\mathrm{D}$ group suggest an association of a more pronounced electrical silence EEG during SACP with the development of a reversible or nonreversible neurological deficit. In addition to temperature and drug effects, perfusion disturbances causing reduced oxygen supply might be responsible for the higher decrease of BIS during SACP in the $\mathrm{N}$ - and D-group. However, this hypothesis seems limited by the use of only unilateral placement of BIS electrodes, mainly on the left forehead. 
In patients who died, mean $\mathrm{rScO}_{2} \mathrm{AUC}$ on both sides of the forehead, but in particular the $\mathrm{rScO}_{2} \mathrm{AUC}$ on the left forehead were found to be higher compared to those of the surviving patients. However, this observation could not be determined to be significant. In the two patients who developed severe cerebral infarction the $\mathrm{rScO}_{2} \mathrm{AUC}$ value was only in one case associated with a corresponding injured cerebral hemisphere. In all other patients who died, death was not caused by cerebral injury but due to multiorgan failure within the framework of intraoperative hemorrhagic shock necessitating massive transfusion. The high $\mathrm{rScO}_{2} \mathrm{AUC}$ values measured in these patients might suggest a role of NIRS in detecting general perfusion disturbances of the whole body, as already published by Fischer and colleagues [31].

In patients suffering type A aortic dissection in most cases the cerebral vascular condition, possible modifications of the cerebral autoregulation and the circle of willis variability is unknown. Application the NIRS optodes at the forehead should provide an estimate of cortical tissue oxygen saturation about $1 \mathrm{~cm}^{2}$ areas of brain in the watershed region at the confluence of anterior and middle cerebral arteries and may thus detect hypo-or hyperperfusion in the anterior circulation. However, this does not provide information on other areas of the brain, including brain stem, middle and posterior cerebral circulation and on areas with impaired perfusion caused by atherosclerosis. Because data on the specificity of $\mathrm{rScO}_{2}$ monitoring for ensuring cerebral perfusion are currently not available, there is little evidence on whether the absence of acute reductions in $\mathrm{rScO}_{2}$ ensures adequate cerebral blood flow in the measured area. While in deep hypothermia and SCAP the cerebral autoregulation is largely retained, the reheating phase leads to marked disturbances of the cerebral autoregulation, leading to states of possible hypo-or hyperperfusion [32]. Especially in this phase the contamination of the $\mathrm{rScO}_{2}$ measure by oxygen saturation of the extracerebral tissue is increasing and makes a safe assessment and estimation of the $\mathrm{rScO}_{2}$ difficult. Conversely, the extent to which the extracerebral oxygen desaturation due to vasoconstriction of the peripheral vessels influences the $\mathrm{rScO}_{2}$ measured by the NIRS is not sufficiently investigated. In addition to physiological and anatomical factors intraoperative changes in the fluid content of the tissues as development of postoperative edema and circulation-assisted pharmacotherapy have significant impact on the $\mathrm{rScO}_{2}$ measure and may explain the results of this investigation.

Being aware of the limitations of this investigation we would like to highlight the retrospective design and the need for offline calculation of the $\mathrm{rScO}_{2}$ AUC values. Although no malposition of cannulas during SCAP have been observed, within the interval between two respective documented values, small but also substantial changes of the $\mathrm{rScO}_{2}$ may have occurred. Unrecorded minor changes of the $\mathrm{rScO}_{2}$ could have a significant impact on an offline calculation of the $\mathrm{rScO}_{2}$ AUC. All intraoperative recorded quantitative and continuous data were collected from the anesthesia protocol, where the data was only periodically documented. That no medium or long-term outcome data was collected from the released reports of the university hospital and the hospitals to which the patients were transferred to for further treatment is a non incisive further limitation of this analysis.

In addition, we defined perilous levels of cerebral desaturation as a drop of $\mathrm{rScO}_{2}$ at each hemisphere $>20 \%$ from the baseline or a drop of the absolute $\mathrm{rScO}_{2}$ value to $<50 \%$. However, there is no consensus in the literature as to the level of cerebral oxygenation that constitutes a significant desaturation during cardiac surgery. Although, Murkin and colleagues considered the area under the curve of saturations $<70 \%$ of baseline and defined $\mathrm{rScO}_{2}$ AUC $>150 \%-\mathrm{min}$ as a measure of profound desaturation, they could not show a significant difference in the neurologic outcome in the treatment compared to the non-treatment group [23]. In a recent study by Slater and colleagues a calculated $\mathrm{rScO}_{2}$ score of $>3000 \%$ seconds was associated with an increased risk of neurocognitive decline and longer hospital stay in 240 coronary artery bypass surgery patients if the absolute $\mathrm{rScO}_{2}$ value dropped < $50 \%$ [24]. In our retrospective investigation patients without any decrease of the $\mathrm{rScO}_{2}>20 \%$ and therefore no $\mathrm{rScO}_{2}$ AUC have developed a reversible neurological deficit. Finally, the only small number of patients included in this investigation may possible effect the outcome. In particular, the considerable number of excluded anesthesia protocols in which documented data was inaccurate; either missing, not clearly readable or not assignable, could have had a relevant impact on our results.

\section{Conclusion}

Regional cerebral oxygenation saturation measurement by near infrared spectroscopy with the INVOS 5100 device does not appear to detect or predict nonreversible or reversible neurological deficit in patients with aortic dissection type A undergoing aortic arch surgery with selective antegrade cerebral perfusion.

\section{Acknowledgements}

We would like to thank Mrs Nina Kloth, MD for correcting the linguistic design of the manuscript.

\section{References}

[1]. Lu S, Yang S, Lai H, Zheng J, Hong T, et al., (2016) Open aortic arch reconstruction for acute type a aortic dissection: a single-center experience with 267 consecutive patients. J Cardiothorac Surg. 11(1): 111.

[2]. Tsai TT, Trimarchi S, Nienaber CA (2009) Acute aortic dissection: perspectives from the International Registry of Acute Aortic Dissection (IRAD). Eur J Vasc Endovasc Surg. 37(2): 149-159.

[3]. Arsalan M, Squiers JJ, Herbert MA, MacHannaford JC, Chamogeorgakis T, et al., (2017) Comparison of Outcomes of Operative Therapy for Acute Type A Aortic Dissections Provided at High-Volume Versus Low-Volume Medical Centers in North Texas. Am J Cardiol. 2 119(2): 323-327.

[4]. Kruger T, Conzelmann LO, Bonser RS, Borger MA, Czerny M, et al., (2012) Acute aortic dissection type A. Br J Surg. 99(10): 1331-1344.

[5]. Tsukube T, Hayashi T, Kawahira T, Haraguchi T, Matsukawa R, et al., (2011) Neurological outcomes after immediate aortic repair for acute type A aortic dissection complicated by coma. Circulation. 124(11): S163-167.

[6]. Lee SJ, Kim JH, Na CY, Oh SS, Kim YM, et al., (2013) Eleven years of experience with the neurologic complications in Korean patients with acute aortic dissection: a retrospective study. BMC Neurol. 13: 46.

[7]. Liu Z, Pang X, Zhang C, Cao G, Fang C, et al., (2016) Incidence and risk factors of delirium in patients after type-A aortic dissection surgerey. J Cardithorac Vasc Anesth. Pii: S1053-0770.

[8]. Spielvogel D, Tang GH (2013) Selective cerebral perfusion for cerebral protection: what we do know. Ann Cardiothorac Surg. 2(3): 326-330.

[9]. De Paulis R, Czerny M, Weltert L, Bavaria J, Borger MA, et al., (2015) Current trends in cannulation and neuroprotection during surgery of the aortic arch in Europe. Eur J Cardiothorac Surg. 47(5): 917-923.

[10]. Olsson C, Thelin S (2006) Regional cerebral saturation monitoring with near-infrared spectroscopy during selective antegrade cerebral perfusion: diagnostic performance and relationship to postoperative stroke. J Thorac Cardiovasc Surg. 131(2): 371-379.

[11]. Harrer M, Waldenberger FR, Weiss G, Folkmann S, Gorlitzer M, et al., 
(2010) Aortic arch surgery using bilateral antegrade selective cerebral perfusion in combination with near-infrared spectroscopy. Eur J Cardiothorac Surg. 38(5): 561-567.

[12]. Rubio A, Hakami L, Munch F, Tandler R, Harig F, et al., (2008) Noninvasive control of adequate cerebral oxygenation during low-flow antegrade selective cerebral perfusion on adults and infants in the aortic arch surgery. J Card Surg. 23(5): 474-479.

[13]. Orihashi K, Sueda T, Okada K, Imai K (2005) Malposition of selective cerebral perfusion catheter is not a rare event. Eur J Cardiothorac Surg. 27(4): 644-648.

[14]. Urbanski PP, Lenos A, Kolowca M, Bougioukakis P, Keller G, et al., (2013) Near-infrared spectroscopy for neuromonitoring of unilateral cerebral perfusion. Eur J Cardiothorac Surg. 43(6): 1140-1144.

[15]. Reents W, Muellges W, Franke D, Babin-Ebell J, Elert O (2002) Cerebral oxygen saturation assessed by near-infrared spectroscopy during coronary artery bypass grafting and early postoperative cognitive function. Ann Thorac Surg. 74(1): 109-114.

[16]. McMahon MA, Squirrell CA (2010) Multidetector CT of Aortic Dissection: A Pictorial Review. Radiographics. 30(2): 445-460.

[17]. Bachet J (2012) Re: Selective cerebral perfusion using moderate flow in complex cardiac surgery provides sufficient neuroprotection. Are children young adults? Eur J Cardiothorac Surg. 42(4): 710-711.

[18]. Li B, Ma WG, Liu YM, Sun LZ (2015) Is extended arch replacement justified for acute type A aortic dissection? Interact Cardiovasc Thorac Surg. 20(1): 120-126.

[19]. Owen-Reece H, Smith M, Elwell CE, Goldstone JC (1999) Near infrared spectroscopy. Br J Anaesth 82(3): 418-426.

[20]. Wahr JA, Tremper KK, Samra S, Delpy DT (1996) Near-infrared spectroscopy: theory and applications. J Cardiothorac Vasc Anesth. 10(3): 406-418.

[21]. Matcher SJ, Kirkpatrick PJ, Nahid K, Cope M, Delpy DT (1995) Absolute quantification methods in tissue near-infrared spectroscopy. Proc SPIE. 2389: 486-495.
[22]. Samra SK, Dy EA, Welch K, Dorje P, Zelenock GB, et al., (2000) Evaluation of a cerebral oximeter as a monitor of cerebral ischemia during carotid endarterectomy. Anesthesiology. 93(4): 964-970.

[23]. Murkin JM, Adams SJ, Novick RJ, Quantz M, Bainbridge D, et al., (2007) Monitoring brain oxygen saturation during coronary bypass surgery: a randomized, prospective study. Anesth Analg. 104(1): 51-58.

[24]. Slater JP, Guarino T, Stack J, Vinod K, Bustami RT, et al., (2009) Cerebral oxygen desaturation predicts cognitive decline and longer hospital stay after cardiac surgery. Ann Thorac Surg 87(1): 36-44; discussion 44-35.

[25]. Edmonds HL Jr (2002) Multi-modality neurophysiologic monitoring for cardiac surgery. Heart Surg Forum. 5(3): 225-228.

[26]. Zanatta P, Forti A (2011) Effectiveness of NIRS to sample the frontal brain cortex in all cardiac surgery patients. Minerva Anestesiol. 77(11): 11241125 .

[27]. McManus J, Pathansali R, Stewart R, Macdonald A, Jackson S (2007) Delirium post-stroke. Age Ageing. 36(6): 613-618.

[28]. Stecker MM, Cheung AT, Pochettino A, Kent GP, Patterson T, et al., (2001) Deep hypothermic circulatory arrest: I. Effects of cooling on electroencephalogram and evoked potentials. Ann Thorac Surg. 71(1): 14-21.

[29]. Bruhn J, Bouillon TW, Shafer SL (2000) Bispectral index (BIS) and burst suppression: revealing a part of the BIS algorithm. J Clin Monit Comput. 16(8): 593-596.

[30]. Tobias JD (2008) Bispectral index monitoring documents burst suppression during pentobarbital coma. J Intensive Care Med. 23(4): 258-262.

[31]. Fischer GW, Lin HM, Krol M, Galati MF, Di Luozzo G, et al., (2011) Noninvasive cerebral oxygenation may predict outcome in patients undergoing aortic arch surgery. J Thorac Cardiovasc Surg. 141(3): 815-821.

[32]. Ono M, Brown C, Lee Jk, Gottesman RF, Kraut M, et al., (2013) Cerebral Blood flow autoregulation is preserved after hyperherpmic circulatory arrest. Ann Thorac Surg. 96(6): 2045. 